\title{
Long-Term Consequences of Switching Handedness: A Positron Emission Tomography Study on Handwriting in "Converted" Left-Handers
}

\author{
Hartwig R. Siebner, ${ }^{1,2}$ Claus Limmer, ${ }^{2}$ Alexander Peinemann, ${ }^{2}$ Alexander Drzezga, ${ }^{3}$ Bastiaan R. Bloem, ${ }^{1}$ \\ Markus Schwaiger, ${ }^{3}$ and Bastian Conrad ${ }^{2}$ \\ 1Sobell Department of Neurophysiology, Institute of Neurology, London WC1N 3BG, United Kingdom, and Departments \\ of ${ }^{2 N e u r o l o g y}$ and ${ }^{3}$ Nuclear Medicine, Technical University Munich, D-81675 Munich, Germany
}

\begin{abstract}
Until some decades ago, left-handed children who attended German schools were forced to learn to write with their right hand. To explore the long-term consequences of switching handedness, we studied the functional neuroanatomy of handwriting in 11 adult "converted" left-handers and 11 agematched right-handers. All participants had used exclusively their right hand for writing since early childhood. Using $\left[{ }^{15} \mathrm{O}\right] \mathrm{H}_{2} \mathrm{O}$ positron emission tomography, changes in normalized regional cerebral blood flow (rCBF) were assessed while participants repetitively wrote a stereotyped word with their right hand. The kinematics of handwriting did not differ between converted left-handers and right-handers. In innate righthanders, handwriting caused a preponderant left-hemispheric activation of parietal and premotor association areas. In contrast, converted left-handers demonstrated a more bilateral activation pattern with distinct activation foci in the right lateral premotor, parietal, and temporal cortex. Moreover, foci in the
\end{abstract}

right rostral supplementary motor area and the right inferior parietal lobule demonstrated a positive linear relationship between the degree of "left-handedness" and normalized rCBF during right-hand writing. Functional activity in the primary sensorimotor cortex was not affected by handedness. Our findings provide evidence for persisting differences in the functional neuroanatomy of handwriting between right-handers and converted left-handers, despite decades of right-hand writing. Right-hemispheric activation in converted left-handers may reflect suppression of unwanted left-hand movements. Alternatively, this activity may represent persistent left-handedness and, as such, demonstrate a hemispheric asymmetry of hand movement representations in cortical motor association areas in relation to the direction and degree of handedness.

Key words: converted left-hander; functional brain imaging; handwriting; handedness; human; plasticity; positron emission tomography; regional cerebral blood flow
Most humans exhibit some degree of handedness, that is, a preference to use one hand for tasks requiring precise coordination, exact calibration of forces, and accurate timing. Approximately $90 \%$ of humans are right-handed and show a lefthemispheric dominance for manual skills (Gilbert and Wysocki, 1992; Porac and Friesen, 2000). It is commonly agreed that handedness is caused by a functional hemispheric asymmetry within the motor network responsible for controlling hand movements. The neurobiological basis for hand preference, however, is still a topic of debate (Peters, 1991; Haaland and Harrington, 1996; Amunts et al., 2000). Several studies on hemispheric dominance related to hand preference have provided evidence for interhemispheric structural and functional differences in the primary sensorimotor cortex (SM1) related to handedness (Kim et al., 1993; Amunts et al., 1996; Dassonville et al., 1997; Volkmann et al., 1998). It is unclear, however, whether an asymmetry in SM1 merely reflects long-term consequences of hand preference (i.e., use-dependent plasticity) or constitutes a causal factor that drives human handedness. Alternatively, some investigators have attrib-

\footnotetext{
Received July 19, 2001; revised Dec. 5, 2001; accepted Dec. 26, 2001.

This research was supported by the Deutsche Forschungsgemeinschaft (Collaborative Research Centre 462: Sensorimotor processes; Project C3). H.R.S. is currently supported by Deutsche Forschungsgemeinschaft Grant SI 738/1-1. We thank Jon Marsden for skillful editing of this manuscript.

Correspondence should be addressed to Dr. Hartwig Roman Siebner, Sobell Department of Neurophysiology, Institute of Neurology, 8-11 Queen Square, London WC1N 3BG, UK. E-mail: h.siebner@ion.ucl.ac.uk.

Copyright (C) 2002 Society for Neuroscience $0270-6474 / 02 / 222816-10 \$ 15.00 / 0$
}

uted handedness to a hemispheric asymmetry of cortical motor association areas, especially in the frontal premotor cortex (Peters, 1991; Haaland and Harrington, 1996).

Studies on "converted" left-handers offer a unique opportunity to gain deeper insights into the functional neuroanatomy of human hand preference. Until some decades ago, innately lefthanded children who attended German schools were often forced to use their right hand for writing. Because of life-long practice, these converted left-handers became as proficient at right-hand writing as innate right-handers. Yet most of these converted left-handers continued to use their left hand for other manual skills, which were less subject to social control. Indeed, attempts to switch handedness usually failed to establish a consistent preference for the right hand in innately left-handed subjects (Porac and Buller, 1990). Such considerations raise the question of whether converted left-handers use the same brain areas as innate right-handers for the selection and execution of handwriting and how much (covert) left-handedness might persist during right-hand writing in converted left-handers.

To address this issue, we investigated the functional neuroanatomy of right-hand writing in converted left-handers and innate right-handers. Because most converted left-handers still demonstrate overt left-handedness during manual skills other than handwriting (Porac and Buller, 1990), we postulated that the functional neuroanatomy of right-hand writing in converted left-handers would differ from innately right-handers, showing persisting features of covert left-handedness. We further predicted that both 
executive motor areas (especially SM1) and motor association areas, which are involved in "higher-order" aspects of manual motor control, would demonstrate a functional interhemispheric asymmetry during right-hand writing depending on the direction and degree of handedness.

\section{MATERIALS AND METHODS}

Subjects. Participants were recruited through announcements at our medical school specifically calling for participation in a study relating to functional correlates of handedness. Each subject's medical history was assessed using a questionnaire. Inclusion criteria were defined as follows: (1) normal achievement of motor developmental milestones during childhood; (2) estimated time spent for handwriting $>5 \mathrm{~min} / \mathrm{d}$; (3) no history of a neuropsychiatric disease; (4) no history of early brain damage, especially perinatal complications; and (5) no report of a temporary shift in hand use caused by injury of the preferred hand.

Eleven converted left-handers (4 women and 7 men, ages 34-64 years, mean age 47 years) and 11 right-handed adults ( 2 women and 9 men, ages $26-58$ years, mean age 42 years) who met the inclusion criteria participated in the experiment after giving written informed consent before the experiment. Permission to administer radioactive isotopes was obtained from the German radiation protection authorities, and the study had the approval of the Ethics Committee of the Faculty of Medicine of the Technische Universität München.

Handedness was classified according to self-report. Participants were assigned to the group of converted left-handers if they met two criteria: (1) a preferred use of their left hand for skillful manual activities throughout their life and (2) a forced change in hand use for the "target activity" of handwriting based on educational pressure. All converted left-handers clearly recalled that they had started to write with their left hand and were subsequently forced to switch to right-hand writing by their teachers and parents during the first year of education (at the age of $\sim 6$ years). The degree of handedness at the time of the study was assessed by the 10-item version of the Edinburgh Handedness Inventory (Oldfield, 1971), which enabled us to calculate a laterality quotient in the range of -100 to +100 . Extreme right-handedness corresponds to a laterality quotient of +100 , whereas a laterality quotient of -100 indicates extreme left-handedness. The absolute value of the laterality quotient was taken as a quantitative measure of individual hand preference in both right-handers and converted left-handers. Familial lefthandedness was determined by the presence of at least one first-degree relative (parent and/or sibling) reported as being left-handed. The posture of the writing hand was classified as either "inverted" or "noninverted" depending on the relative position of the hand relative to the line of writing (Teasdale and Owen, 2001). Hand posture was classified as noninverted if the writing hand was positioned below or in parallel to the line of writing and the pen was pointed away from the writer. Writing posture was labeled as inverted posture if the writing hand was held above the line of writing and the pen hooked back toward the writer.

Experimental design. We used $\left[{ }^{15} \mathrm{O}^{\mathrm{H}} \mathrm{H}_{2} \mathrm{O}\right.$ positron emission tomography (PET) to study changes in regional cerebral blood flow (rCBF) while subjects wrote with their right hand. Each participant underwent six consecutive $\left[{ }^{15} \mathrm{O}\right] \mathrm{H}_{2} \mathrm{O}$-PET measurements of $\mathrm{rCBF}$ (50 sec duration for each measurement). Subjects were scanned in the supine position in a dimly lit room.

Two conditions were assessed: a handwriting condition (A) and a rest condition (B). The experimental conditions were repeated in an alternating order (either ABABAB or BABABA), which was counterbalanced across subjects. In the handwriting condition, participants repeatedly wrote the German verb "bellen" (i.e., "to bark") with their right hand paced by a tone every $6 \mathrm{sec}$. Because the writing task was paced by a tone, the number of written words was matched across scans. In the rest condition, subjects held the pencil on a writing tablet without writing, while listening to the pacing tone. To facilitate fluent handwriting, participants were instructed to write at their own size and speed. To avoid a change in posture during PET scanning, subjects were asked to reposition their hand to the starting point after having written the word. The first pacing tone was given on injection of the radioisotope. PET data acquisition started $25-35 \mathrm{sec}$ later because of the time delay between intravenous administration of $\left[{ }^{15} \mathrm{O}^{-} \mathrm{H}_{2} \mathrm{O}\right.$ and arrival of radioactivity in the brain. Participants continued to write until the end of each $50 \mathrm{sec}$ PET scan. Thus, the first four to six words were actually written before PET scanning, and only the writing of the last eight words coincided with the period of PET data acquisition. This allowed the subjects to get into a routine of task performance before each PET scan. In addition, this procedure minimized the influence related to possible differences in task initiation across the three groups.

The rationale to select handwriting as the motor task was threefold. First, hand preference is expressed primarily during the performance of highly complex manual skills such as handwriting. Second, because environmental pressure against use of the left hand was particularly concerned with handwriting in Germany, other manual tasks were switched to a lesser extent and thus are expected to be less sensitive than handwriting in demonstrating the functional consequences of switching handedness. Third, because participants wrote with their right hand throughout their life, there should not be any between-group differences regarding long-term motor practice. This may not be true for other manual skills, which most converted left-handers continue to perform with their preferred left hand (Porac and Buller, 1990).

A relatively simple word was selected for the writing task to minimize semantic processing during the writing task. No visual feedback was provided during handwriting. Before PET scanning, subjects were trained for $10 \mathrm{~min}$ to perform the writing task in a supine position without visual feedback. Training was performed in the PET scanner and subjects wrote the same word that they had to produce during PET scanning.

During PET scanning, handwriting was continuously recorded using a digitizing graphics tablet (UD-1212; Wacom Europe GmbH, Neuss, Germany). The writing board was placed over the participant's legs with the surface of the board angled at $45^{\circ}$ to the horizontal plane. To minimize movements of proximal joints and to match the posture of the hand as close as possible to the normal position during handwriting, the right upper limb was comfortably supported by foam plastic pads and participants were required to place the ulnar part of their right hand on the writing board while they were writing. Pen-tip position of an inking digitizing pen was stored on a personal computer with a sample frequency of $166 \mathrm{~Hz}$. The spatial resolution was $0.05 \mathrm{~mm}$, and the accuracy was $0.025 \mathrm{~mm}$ in the horizontal and vertical direction. Velocity and acceleration signals were calculated and smoothed by nonparametric regression methods (Marquardt and Mai, 1994).

For each PET scan, only the eight words that were written during the $50 \mathrm{sec}$ period of data acquisition were included in kinematic analysis. Kinematic analysis used a PC-based writing analysis program of single upstrokes and downstrokes (CS-Software; MedCom, Munich, Germany). Movements were segmented in subsequent vertical upstrokes or downstrokes of the pencil, which represent the fundamental modules of regular writing (Hollerbach, 1981; Morasso and Mussa Ivaldi, 1982; Plamondon, 1995). A single stroke is defined as the time segment between two subsequent changes in vertical direction of handwriting. Upstrokes and downstrokes with a duration of $<50 \mathrm{msec}$ were excluded from kinematic analysis. The following dimensions of writing performance were calculated for each word: vertical stroke length, vertical stroke duration, and peak vertical writing velocity. Furthermore, the number of inversions in velocity (NIV) per single stroke was estimated to quantify the degree of automation of the handwriting movements (Marquardt and Mai, 1994). An NIV of one per stroke is characteristic of fast open-loop performance, whereas an increase in mean NIV per stroke indicates continuous adjustments of writing velocity to the incoming feedback information during slow closed-loop handwriting (Eichhorn et al., 1996; Marquardt et al., 1999; Siebner et al., 1999).

Each kinematic variable was analyzed separately using an ANOVA for repeated measurements (SPSS version 9; SPSS Inc., Chicago, IL). The within-subject factor was "order of PET scans" with three levels (PET scan 1, PET scan 2, and PET scan 3). The between-subject factor was "group" with three levels (converted left-handers, nonconverted lefthanders, and innate right-handers). Significance was accepted at a value of $p=0.05$.

Positron emission tomography. The rCBF was measured by recording the regional distribution of radioactivity after the intravenous injection of ${ }^{15}$ O-labeled water (Fox and Mintun, 1989). PET scans were obtained in three-dimensional mode using a Siemens ECAT $951 \mathrm{R} / 31$ PET scanner (CTI Inc., Knoxville, TN). For each measurement of rCBF, $250 \mathrm{mBq}$ of $\left[{ }^{15} \mathrm{O}\right] \mathrm{H}_{2} \mathrm{O}$ was administered in the left cubital vein as a semibolus injection using an infusion pump. A $50 \mathrm{sec}$ PET scan was initiated when a rising radioactivity count in the brain was first detected $(\sim 30 \mathrm{sec}$ after radioisotope injection). After corrections for randoms, dead time, and scatter, all emission data were reconstructed by filtered backprojection (Hanning filter; 0.5 cycles/pixel cutoff frequency) to 31 consecutive axial planes with an interplane separation of $3.375 \mathrm{~mm}$. Reconstructed slices 
were displayed in a matrix consisting of $128 \times 128$ voxels. The interscan interval was $\sim 10 \mathrm{~min}$. A $20 \mathrm{~min}$ headholder transmission scan with a rotating ${ }^{68} \mathrm{Ge} /{ }^{68} \mathrm{Ga}$ source was obtained before each session and used to correct for effects of radiation attenuation. Note that the PET scanner had a total axial view of $10.5 \mathrm{~cm}$ and no interplane dead space, ensuring coverage of the upper two-thirds of the brain from the vertex to the upper cerebellum. All calculations and image transformations were performed on Sun SPARC 2 workstations (Sun Computers Europe, Inc., Surrey, UK). PET data were analyzed using statistical parametric mapping software (http://www.fil.ion.ucl.ac.uk/spm/) implemented in the PRO Matlab environment (Mathworks Inc., Natick, MA). The scans from each subject were realigned using the first scan as a reference. The six parameters of this rigid body transformation were estimated using a least-squares approach on a voxel-by-voxel basis (Friston et al., 1995a). After realignment, PET images were transformed into stereotactic space using a template from the Montreal Neurological Institute (Montreal, Canada). Spatial normalization was performed using linear and nonlinear three-dimensional transformations to match each scan to a reference image that already conformed to the standard stereotaxic space (Friston et al., 1995a). As a final preprocessing step, the normalized images were smoothed using an isotropic Gaussian kernel of $12 \mathrm{~mm}$ full width at half maximum for all directions to increase the signal-to-noise ratio and reduce variance attributable to interindividual differences in gyral anatomy (Friston et al., 1995a). Each voxel of the resulting normalized and smoothed images was $2 \times 2 \times 4 \mathrm{~mm}$ in size.

The effect of changes in global cerebral blood flow across subjects and scans was removed by linear scaling across the entire data set. The mean rCBF value was then arbitrarily normalized to a global mean of 50 $\mathrm{ml} \cdot 100 \mathrm{ml}^{-1} \cdot \min ^{-1}$. The adjusted voxel values were then used for additional statistical analysis (Friston et al., 1990). The statistical analysis was performed according to the general linear model and the theory of Gaussian fields at each and every voxel (Friston et al., 1991, 1995b; Worsley et al., 1992). The resulting statistical parametric maps based on the $t$ statistic were subsequently transformed into normally distributed statistical parametric $Z$ maps (Friston et al., 1995b). The locations of peak activations were reported as stereotaxic coordinates according to the system introduced by Talairach and Tournoux (1988).

PET data were analyzed in three different ways: First, using linear weighted contrasts, a within-group subtraction analysis between the writing condition and the baseline condition was performed to define those brain areas that were functionally active during right-hand writing in right-handers and converted left-handers. The significance level was set at a value of $p=0.05$ after correction for multiple nonindependent comparisons, which corresponds to a $Z$ score of 4.26. Brain areas showing increases in rCBF at an uncorrected value of $p<0.001$ (corresponding to a $Z$ score of 3.09) but that did not survive correction for multiple nonindependent comparisons were considered as trend activations.

In a second set of analyses, we explored specific regional differences in the handwriting-induced activation pattern between right-handers and converted left-handers. Using appropriately weighted linear contrasts, a between-group subtraction analysis was computed to pinpoint those brain areas that showed stepwise differences in writing-related functional activation depending on the direction of handedness. Both resting scans and activation scans were included in the design matrix of the between-group subtraction analysis.

Although suitable to map stepwise differences in activation changes across groups, between-group subtraction analysis may fail to detect those brain areas that gradually scale their activity according to a given variable, such as the degree of handedness. Therefore, we computed a third independent ANCOVA with the individual laterality quotient of each participant being treated as a "covariate of interest" to delineate those brain areas that show a linear relationship between functional activation during handwriting and the degree of handedness. In contrast to between-group subtraction analysis, only PET scans acquired during handwriting were included in the design matrix.

As for between-group analyses, an uncorrected value of $p=0.001$ was accepted as a statistical threshold for those brain regions that had already shown at least trend activation during right-hand writing, as indicated by within-group analyses. Otherwise, significance level was set at a corrected value of $p=0.05$. Foci revealing a differential activation that exceeded an uncorrected value of $p=0.001$ but did not reach a corrected value of $p=0.05$ are only descriptively reported. This approach provided a reasonable trade-off between a maximized sensitivity of data analysis and an increased risk for false positives (Boecker et al., 1998).

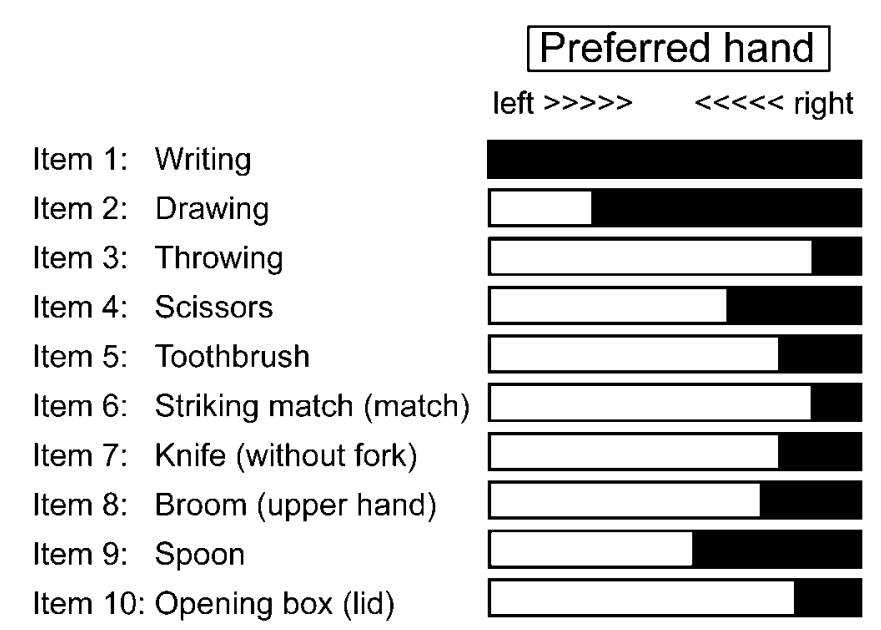

Figure 1. Relative distribution of hand preference across the 10 items of the Edinburgh handedness inventory (Oldfield, 1971) in the group of converted left-handers $(n=11)$. Each horizontal bar provides a visual analog scale for the right-to-left ratio of hand preference for the individual items. For each bar, the black area indicates preferred use of the right hand, whereas the white area indicates preferred use of the left hand. Note that converted left-handers showed a consistent right-hand preference for writing only.

Control experiment. To investigate left-hand writing in innate lefthanders who were not switched to the right hand for handwriting, we studied six left-handers (one woman and five men, ages 25-55 years, mean age 32 years) who used exclusively their left hand for writing in daily life. Because most middle-aged and elderly left-handers who live in Germany had been switched to the right hand for handwriting, we failed to recruit an age-matched control group of nonconverted left-handers. This explains why consistent left-handers were on average 15 years younger than converted left-handers. The laterality quotient ranged from -80 to -100 , indicating that all participants were consistent left-handers (Oldfield, 1971). Apart from the fact that participants were required to write with their left hand, the control experiment was identical to the main experiment. This control experiment represents a descriptive approach to estimate the "normal" cerebral representations of left-hand writing in nonconverted left-handers. In view of the insufficient age matching, only a within-group subtraction analysis between left-hand writing and baseline (holding the pencil) was computed.

\section{RESULTS}

\section{Degree and history of handedness}

Innate right-handers showed little interindividual variability of handedness, with laterality quotients ranging from +80 to +100 (mean laterality quotient 96), whereas the magnitude of lefthandedness was more variable among converted left-handers with laterality quotients ranging from -80 to +40 (mean laterality quotient -29). Figure 1 illustrates the relative frequency for right-hand use and left-hand use for each individual item of the Oldfield questionnaire in the group of converted left-handers. Apart from writing, which was consistently performed with the right hand, a preferential use of the right hand was relatively often reported for everyday manual activities, such as drawing or handling a spoon (Fig. 1). Use of the right hand during these activities was often enforced throughout the education period.

Five converted left-handers had a familial history of lefthandedness, as opposed to only one innate right-hander. In the group of consistent left-handers, two of six subjects reported having at least one left-handed first-degree relative.

All innate right-handers and converted left-handers used a noninverted posture for handwriting. In contrast, writing posture was not standardized in the group of consistent left-handers. 
Table 1. Average group values ( \pm SD) of kinematic variables

\begin{tabular}{|c|c|c|c|c|c|c|c|c|c|}
\hline \multirow[b]{2}{*}{ Kinematic measures } & \multicolumn{3}{|c|}{ Innate right-handers } & \multicolumn{3}{|c|}{ Converted left-handers } & \multicolumn{3}{|c|}{ Innate left-handers } \\
\hline & Scan 1 & Scan 2 & Scan 3 & Scan 1 & Scan 2 & Scan 3 & Scan 1 & Scan 2 & Scan 3 \\
\hline Vertical stroke length (mm) & $6.9(3.2)$ & $7.1(3.8)$ & $7.0(2.8)$ & $6.5(3.0)$ & $6.6(3.7)$ & $7.2(4.7)$ & $7.1(4.9)$ & $6.7(5.2)$ & $6.5(5.3)$ \\
\hline Vertical stroke duration (msec) & $144(30)$ & $139(24)$ & $140(23)$ & $138(25)$ & $136(26)$ & $139(24)$ & $131(24)$ & $132(28)$ & $135(33)$ \\
\hline Vertical writing velocity $(\mathrm{mm} / \mathrm{sec})$ & $62(29)$ & $67(39)$ & $65(28)$ & $63(25)$ & $62(29)$ & $67(38)$ & $66(40)$ & $63(26)$ & $60(28)$ \\
\hline $\begin{array}{l}\text { Numbers of inversions in velocity } \\
\text { per vertical stroke }\end{array}$ & $1.39(0.37)$ & $1.41(0.40)$ & $1.34(0.34)$ & $1.30(0.24)$ & $1.26(0.24)$ & $1.28(0.22)$ & $1.46(0.24)$ & $1.43(0.31)$ & $1.48(0.25)$ \\
\hline
\end{tabular}
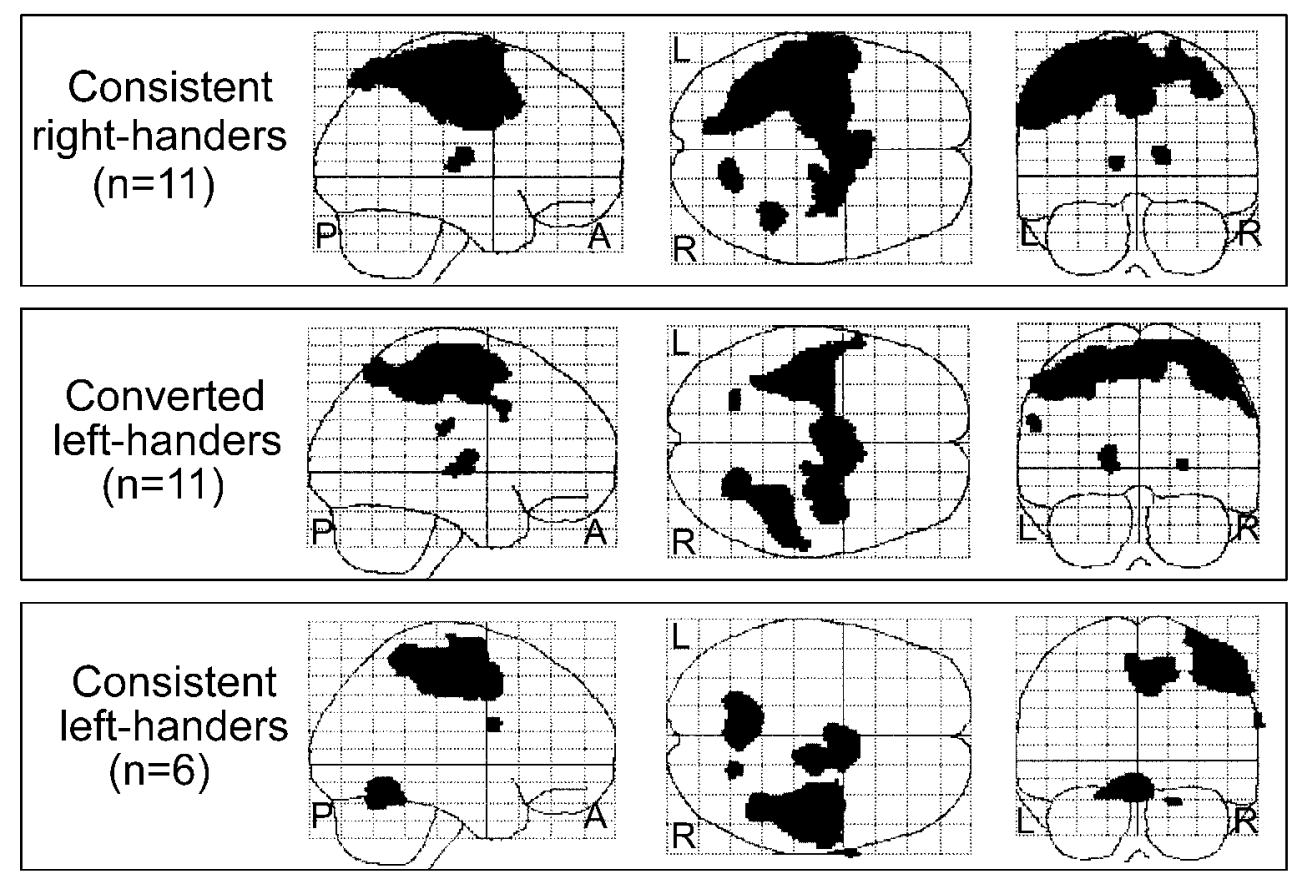

Figure 2. Statistical parametric maps displayed as through-projections onto representations of stereotaxic space in a socalled "glass brain" view, corresponding to sagittal, coronal, and axial projections. All voxels that were significant at $p<$ 0.001 (uncorrected) are displayed as black overlays for three within-group analyses: relative increases in normalized $\mathrm{rCBF}$ during right-hand writing in 11 innate right-handers (top), relative increases in normalized $\mathrm{rCBF}$ during right-hand writing in 11 converted left-handers (middle) and relative increases in normalized $\mathrm{rCBF}$ during left-hand writing in six consistent left-handers (bottom). $P$, Posterior; $A$, anterior; $L$, left; $R$, right.

Three consistent left-handers used an inverted posture of handwriting, whereas the remaining three used a noninverted position.

\section{Kinematic data}

Innate right-handers needed a mean total movement time of $2.29 \pm 0.61 \mathrm{sec}$, and converted left-handers required $2.21 \pm 0.59$ sec to write a single target word. Table 1 gives the average group values of each kinematic variable for innate right-handers and converted and nonconverted left-handers. Repeated-measures ANOVA showed no significant group effect on any of the kinematic variables of interest, indicating that motor performance was well matched between right-handers and left-handers. In both groups, kinematics of handwriting movements were highly automated, as evidenced by a mean number of inversions in velocity per stroke below 2. Furthermore, there was no significant effect of order of PET scans and no significant interaction term between the factors order of PET scans and group, confirming stable motor performance throughout the PET experiment after $10 \mathrm{~min}$ of training. In each participant, $>98 \%$ of the recorded strokes met predefined criteria and were included in the kinematic analysis.

\section{PET data}

\section{Within-group subtraction analyses}

In innate right-handers, handwriting caused a significant relative increase in normalized $\mathrm{rCBF}$ in a large bihemispheric cortical cluster, with a preponderant activation of left-hemispheric re- gions (Fig. 2, Table 2). In the left hemisphere, right-hand writing activated most of the components of the frontoparietal cortex that have been shown to be involved in the generation of skilled hand movements, with the foci of strongest activation being located in the left SM1, the left caudal supplementary motor area (SMA), and the left dorsal lateral premotor cortex (LPC). In addition to a widespread increase in the left parietal cortex, including most of the superior and inferior parietal lobule, there were two foci of activation in the right parietal cortex, namely in the right precuneus and the right anterior intraparietal sulcus. Converted lefthanders demonstrated a similar activation pattern during righthand writing, when contrasting the writing condition to the resting condition (Fig. 2, Table 2). Functional activation was considerably less lateralized to the left hemisphere, however, showing a relative shift in handwriting-evoked activation from left to right frontoparietal motor areas. For instance, converted left-handers showed a distinct peak of activation in the right dorsal LPC and a strong activation of the right superior and inferior parietal lobule (Fig. 2, Table 2). Subcortically, innate right-handers showed a bilateral activation in the thalamus during handwriting, whereas converted left-handers demonstrated an activation in the right thalamus and the left globus pallidus (Fig. 2, Table 2). In the control experiment on six consistent lefthanders, within-group analysis revealed a strong righthemispheric lateralization of cortical activity during left-handed writing (Fig. 2, Table 2). 


\begin{tabular}{|c|c|c|c|c|}
\hline \multirow{2}{*}{$\begin{array}{l}\text { Activated brain regions during } \\
\text { handwriting (Brodmann area) }\end{array}$} & \multirow{2}{*}{$\begin{array}{l}Z \text { score of peak } \\
\text { activation }\end{array}$} & \multicolumn{3}{|c|}{ Coordinates of peak activation $(\mathrm{mm})$} \\
\hline & & $x$ & $y$ & $z$ \\
\hline \multicolumn{5}{|c|}{ Innate right-handers $(n=11)$ : right-hand writing } \\
\hline Left primary sensorimotor cortex $(3 / 4)$ & 7.09 & -38 & -24 & 58 \\
\hline Caudal supplementary motor area (6) & 6.70 & -16 & -8 & 56 \\
\hline Left dorsal premotor cortex (6) & 6.59 & -26 & -8 & 60 \\
\hline Right precuneus (7) & 4.3 & 18 & -64 & 62 \\
\hline Left thalamus & $3.70^{*}$ & -12 & -22 & 8 \\
\hline Right thalamus & $3.64^{*}$ & 14 & -18 & 12 \\
\hline Right anterior intraparietal sulcus & $3.42 *$ & 38 & -44 & 52 \\
\hline \multicolumn{5}{|c|}{ "Converted" left-handers $(n=11)$ : right-hand writing } \\
\hline Left primary sensorimotor cortex $(3 / 4)$ & 6.53 & -38 & -20 & 58 \\
\hline Caudal supplementary motor area (6) & 5.27 & 2 & -4 & 60 \\
\hline Right dorsal premotor cortex (6) & 4.42 & 38 & -2 & 50 \\
\hline Right anterior intraparietal sulcus & 5.80 & 34 & -38 & 52 \\
\hline Right superior parietal lobule (7) & 5.21 & 26 & -60 & 58 \\
\hline Right inferior parietal lobule (40) & 4.77 & 54 & -32 & 48 \\
\hline Right thalamus & $3.79^{*}$ & 18 & -10 & 8 \\
\hline Left precuneus (7) & $3.71^{*}$ & -24 & -62 & 62 \\
\hline Left globus pallidum & $3.57^{*}$ & -24 & -12 & 2 \\
\hline Right parietal operculum & $3.56^{*}$ & 58 & -24 & 24 \\
\hline \multicolumn{5}{|l|}{ Innate left-handers $(n=6)$ : left-hand writing } \\
\hline \multirow[t]{2}{*}{ Right primary sensorimotor cortex $(3 / 4)$} & 5.13 & 52 & -22 & 58 \\
\hline & 4.65 & 48 & -14 & 56 \\
\hline Right anterior intraparietal sulcus & 4.32 & 42 & -46 & 62 \\
\hline Right dorsal premotor cortex (6) & 4.30 & 44 & -6 & 56 \\
\hline Anterior cingulate cortex/caudal SMA & 4.92 & 10 & -20 & 50 \\
\hline Anterior cingulate cortex & 4.86 & 6 & 2 & 48 \\
\hline Cerebellum & 4.98 & -8 & -56 & -16 \\
\hline Right ventral premotor cortex (6) & $3.56^{*}$ & 70 & 4 & 20 \\
\hline
\end{tabular}

The asterisks indicate trend activations (i.e. activations with maximum $Z$ scores ranging between 3.09 and 4.26 ).

Innate right-handers, converted left-handers, and consistent left-handers revealed a similar pattern of reduction in normalized $\mathrm{rCBF}$ during automatic right-hand writing. Significant foci of reduced $\mathrm{rCBF}$ were observed in the medial and lateral prefrontal cortex and occipitoparietal visual association areas. Innate righthanders showed only a right-hemispheric deactivation for the lateral prefrontal cortex, whereas converted left-handers demonstrated a bihemispheric pattern of deactivation.

\section{Between-group subtraction analysis}

Between-group subtraction analysis revealed distinct hemispheric asymmetries in the handwriting-related activation pattern between innate right-handers and converted left-handers. In innate right-handers, left-hemispheric foci in the dorsal and ventral LPC and in the inferior and superior parietal lobule were consistently more activated during writing (Table 3 ). The activity profiles revealed that the left parietal clusters as well as the cluster in the left ventral LPC were selectively activated during the writing condition in the innate right-handed participants only (Fig. 3). In contrast, the focus in the left dorsal LPC was activated during handwriting in both right-handers and converted left-handers, but task-related activation of the left dorsal premotor cortex was more pronounced in innate right-handers (Fig. 3).

With regard to hemispheric asymmetry, a reverse pattern of differential activation emerged in converted left-handers. In converted left-handers, four cortical clusters in the right hemisphere demonstrated a more prominent functional activation during right-hand writing (Fig. 3, Table 3). These areas included foci in the posteromedial part of the right superior temporal gyrus, the right precuneus, the right parietal operculum, and the right LPC. The premotor cluster included two separate peaks of activation, located in the dorsal and ventral part of the LPC. The activity profiles, which describe the relative activation of a given voxel across experimental conditions, revealed that the right superior temporal gyrus, right precuneus, and right parietal operculum including the secondary somatosensory cortex were activated during right-hand writing in converted left-handers as opposed to a relative deactivation of these areas in innate right-handers (Fig. 3 , Table 3). In contrast, the cluster in the right LPC showed some handwriting-induced activation in both groups, with a considerably stronger activation in converted left-handers.

Note that all premotor, parietal, and temporal clusters that demonstrated a differential writing-related activation according to the direction of handedness had also shown at least trend activation in the respective within-group analysis. Lefthemispheric clusters in the premotor and parietal cortex demonstrating a stronger writing-related activation in innate righthanders showed at least trend activation in the within-subject analyses of right-handed participants (Fig. 2, Table 2). Likewise, right-hemispheric clusters in the premotor, parietal, and temporal cortex that displayed a stronger writing-related activation in converted left-handers showed at least trend activation in the withinsubject analyses in converted left-handers (Fig. 2, Table 2). The 


\begin{tabular}{|c|c|c|c|c|}
\hline \multirow{2}{*}{$\begin{array}{l}\text { Activated brain regions (Brodmann } \\
\text { area) }\end{array}$} & \multirow{2}{*}{$\begin{array}{l}Z \text { score of peak } \\
\text { activation }\end{array}$} & \multicolumn{3}{|c|}{$\underline{\text { Coordinates of peak activation }(\mathrm{mm})}$} \\
\hline & & $x$ & $y$ & $z$ \\
\hline \multicolumn{5}{|l|}{ Innate right-handers } \\
\hline Left superior parietal lobule (7) & 3.96 & -26 & -52 & 60 \\
\hline Left precuneus (7) & 3.24 & -12 & -66 & 56 \\
\hline Left inferior parietal lobule (40) & 3.74 & -54 & -32 & 44 \\
\hline Left dorsal premotor cortex (6) & 3.63 & -20 & -8 & 64 \\
\hline Right superior frontal gyrus & $3.61^{*}$ & 10 & 38 & 58 \\
\hline Left ventral premotor cortex (6) & 3.60 & -66 & -10 & 32 \\
\hline \multicolumn{5}{|l|}{ Converted left-handers } \\
\hline Right precuneus (7) & 3.83 & 18 & -44 & 54 \\
\hline \multirow[t]{2}{*}{ Right parietal operculum (1/2) } & 3.74 & 66 & -16 & 22 \\
\hline & 3.67 & 56 & -28 & 22 \\
\hline Right superior temporal gyrus (22) & 3.66 & 40 & -40 & 10 \\
\hline Right dorsal premotor cortex (6) & 3.33 & 44 & -8 & 54 \\
\hline Right ventral premotor cortex (6) & 3.25 & 46 & 0 & 34 \\
\hline Left superior frontal sulcus & $3.25^{*}$ & -26 & 14 & 54 \\
\hline
\end{tabular}

The asterisks indicate brain regions that are located outside the predefined search volume.

considerable spatial overlap of the respective clusters of activation is illustrated in Figure 3, which provides an overlay of the statistical parametric maps for both within-subject analysis and between-subjects analysis.

In both groups, an additional prefrontal cluster was observed that showed a differential effect of handedness on task-related activation (Table 3). In contrast to premotor, temporal, and parietal clusters, however, within-group analyses revealed no trend activation of the prefrontal cortex during handwriting per se. Indeed, the prefrontal cortex was deactivated during automatic right-hand writing. As a consequence, the differential effect on writing-related activation in the prefrontal cortex was attributable to differences in writing-related deactivation rather than writing-related activation (Fig. 3). Because the prefrontal clusters were located outside the predefined brain regions of interest (i.e., those brain regions showing at least trend activation during righthand writing per se as indicated by within-group analyses) and failed to reach an uncorrected value of $p=0.05$, the prefrontal clusters are only descriptively reported.

\section{Correlational analysis}

An additional ANCOVA with the laterality quotient treated as a covariate of interest revealed two cortical areas in the right cerebral hemisphere that showed a linear increase in $\mathrm{rCBF}$ with increasing left-handedness. The first cortical cluster was located in the right inferior parietal lobule within the supramarginal gyrus ( $Z$ score of peak activation, 3.72; Talairach coordinates of peak activation in millimeters, $x, y, z=64,-40,28$, respectively). The second cortical cluster was located in the right rostral SMA extending into the motor area of the right anterior cingulate cortex ( $Z$ score of peak activation, 3.49; Talairach coordinates of peak activation in millimeters, $x, y, z=12,2,56$, respectively; Fig. 4). Both foci had been indicated as brain regions involved in handwriting per se by within-group analysis. No brain area within the field of view of the scanner demonstrated a positive linear relationship between $\mathrm{rCBF}$ and the degree of right-handedness.

\section{DISCUSSION}

Consistent right-handers showed a strong asymmetrical functional activation pattern, with prominent activity in left premotor and parietal areas contralateral to the dominant (writing) hand. Consistent left-handers demonstrated a mirrored activation pattern with preponderant right-hemispheric activation when writing with their dominant left hand. In contrast, converted left-handers demonstrated more symmetrical functional activation during right-hand writing, with a relative increase in right-hemispheric activity of frontoparietal motor association areas ipsilateral to the writing hand.

Because this PET study used only writing as the task of interest, the present study cannot be generalized to other manual skills. Although a control task in which the subjects would have performed manual tasks other than handwriting (e.g., drawing, sequence of key-presses) would have been desirable, there are several problems in defining an appropriate control task that allows a meaningful comparison. First, it would have been difficult to match any control task for executive aspects of the task (i.e., number of submovements and complexity of the movement patterns). Second, the degree of automaticity is likely to differ among tasks because of differences in the amount of daily practice throughout life. Third, handwriting was the only manual skill that was consistently switched in converted left-handers. Thus, other tasks would probably be less sensitive at picking up functional changes associated with switching hand preference.

\section{Premotor cortex}

Using functional magnetic resonance imaging (MRI), Rintjes et al. (1999) mapped the cerebral activation pattern while righthanded subjects wrote their signature with the right index finger or right big toe. The anterior parts of "hand areas" in the dorsal and ventral LPC, as well as the SMA, were activated during both conditions, suggesting an "effector-independent blueprint" of writing in frontal premotor association areas. Our findings suggest that this blueprint is preferentially stored in the left LPC of right-handers and in the right LPC of left-handers. Thus, righthanders demonstrated more prominent activation in the left dorsal and ventral LPC during right-hand writing, whereas a stronger activation of the right LPC was observed in converted left-handers.

Functional imaging studies on innately left- and right-handers substantiate this handedness-dependent functional lateralization 

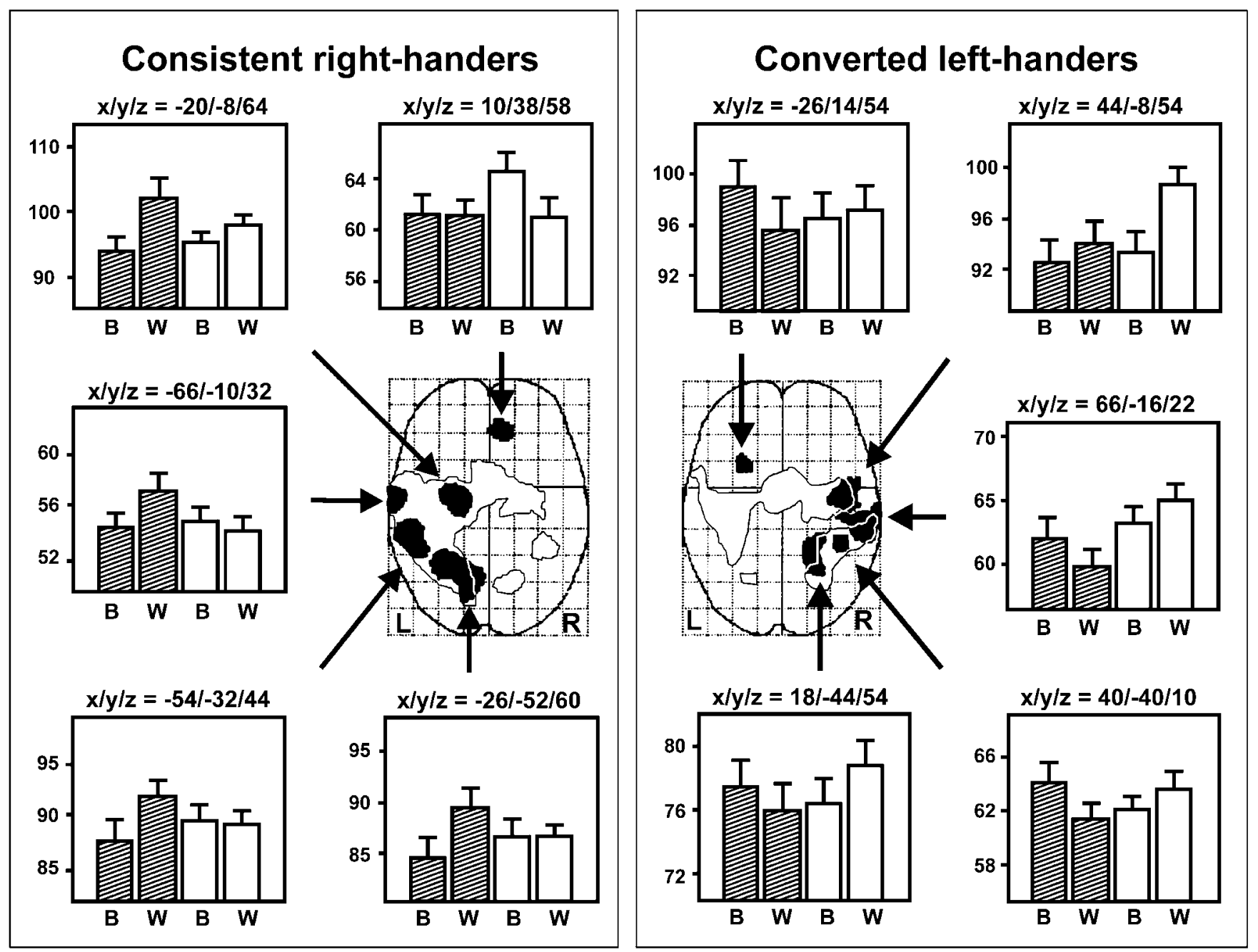

Figure 3. Statistical parametric maps (black areas) and regional activity profiles illustrating between-group differences in handwriting-associated rCBF changes. Left, Cortical regions that showed a relatively stronger writing-associated activation in innate right-handers. Right, Cortical regions with a relatively stronger activation in converted left-handers. Center, Between-group differences in writing-related activation displayed as an axial throughprojection of their statistical parametric maps (black areas). For illustrative purposes, the maps are thresholded at $p<0.01$ (uncorrected). The white areas indicate the respective activation maps during handwriting per se as derived from within-group analyses (Fig. 2). Bars represent regional activity profiles for a single reference voxel that showed maximum differential activation within the corresponding cortical cluster (arrows). The stereotaxic coordinates of each reference voxel are given on top of each bar representation. The adjusted blood flow values in milliliters per $100 \mathrm{ml} / \mathrm{min}$ are given on the ordinate. The columns indicate the mean adjusted rCBF values $( \pm \mathrm{SD})$ for each group (hatched bars, innate right-handers; white bars, converted left-handers) and experimental condition ( $B$, baseline condition; $W$, writing condition; $L$, left; $R$, right).

Figure 4. Sagittal and coronal projections of statistical parametric maps superimposed onto stereotactically normalized T1-weighted magnetic resonance images using the template provided by the Montreal Neurological Institute. The gray lines correspond to Talairach coordinates $x, y, z(+12,+2$, and +56 , respectively, in millimeters). The white area indicates those voxels in the right rostral SMA that showed a linear relationship between the degree of left-handedness and normalized rCBF during right-hand writing. For illustrative purposes, the maps are thresholded at $p<0.01$ (uncorrected). $P$, Posterior; $A$, anterior; $L$, left; $R$, right.
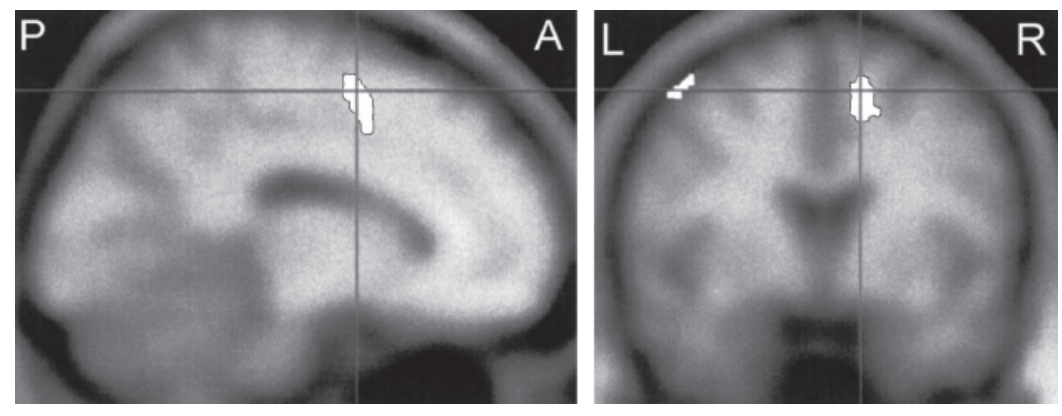

in the LPC. In left-handers, the right dorsal LPC is activated by both contralateral and ipsilateral finger movements, whereas the left dorsal LPC is active only during contralateral finger movements (Kawashima et al., 1997). Furthermore, left-handers preferentially activate the right ventral LPC during cycling move- ments of both hands, but right-handers demonstrate the opposite pattern (Vivani et al., 1998).

In the present study, the right rostral SMA showed a positive linear relationship with the degree of left-handedness. This suggests that the right rostral SMA contributes to adaptive plasticity 
of manual motor control in converted left-handers. Two alternative mechanisms related to task execution or initiation, however, may also contribute. First, converted left-handers perhaps paid more attention to right-hand writing because task execution was more difficult. If present, relative differences in task difficulty could partially account for activation of the rostral SMA, which is involved in higher-order aspects of manual motor control, including a range of supervisory functions (Deiber et al., 1991; Hikosaka et al., 1996; Tanji, 1996; Boecker et al., 1998; Nagahama et al., 1999; Sakai et al., 1999). It is unlikely, however, that discrepancies in task execution explain all activation differences between converted left-handers and right-handers. Right-hand writing was highly overlearned after several decades of everyday practice in both groups, suggesting that right-hand writing was not more complex for converted left-handers. Indeed, kinematic analysis of writing movements confirmed a high and comparable degree of automaticity for both groups. Furthermore, within-group analyses revealed no writing-related activation in the lateral prefrontal cortex and anterior cingulate cortex of either group, suggesting that both right-handers and converted left-handers wrote without paying particular attention (Jenkins et al., 1994; Jueptner et al., 1997; Toni et al., 1998). Significantly, between-group differences in writing-related activity in the medial prefrontal cortex were caused by task-related deactivation, which argues against differences in the amount of active task monitoring during writing.

A second possibility for the differences in rostral SMA activity is that converted left-handers with residual left-handedness have more difficulties in initiating right-hand writing and may also have to inhibit movements with the preferred left hand. Thus, response selection and suppression could cause increased activation of the right rostral SMA, which has been shown to participate in response initiation, selection, and suppression (Deiber et al., 1991, 1996, 1999; Humberstone et al., 1997; Schluter et al., 1998, 2001; Sakai et al., 2000; Waldvogel et al., 2000). Response selection may be activated subconsciously when converted left-handers with strong residual left-handedness engage in manual activities that have been successfully switched to the right hand.

Only the right rostral SMA demonstrated a positive relationship between the degree of left-handedness and the rCBF during right-hand writing. This finding extends previous imaging studies that have observed a functional asymmetry of the rostral SMA (Hikosaka et al., 1996; Deiber et al., 1999), suggesting a complex interhemispheric distribution of activity in the rostral SMA. When learning a new movement sequence, six of eight righthanded subjects showed a predominant focus of learning-related activation in either the right or left pre-SMA, according to the subject (Hikosaka et al., 1996). Furthermore, Deiber et al. (1999) reported a preponderant activation of the right rostral SMA for self-initiated finger movements with the right hand in innate right-handers.

\section{Parietal cortex}

Depending on the direction of handedness, several foci in the rostral parietal cortex showed a biased activation toward one hemisphere during right-hand writing. A focus in the left anterior superior parietal lobule, extending into the precuneus, and a focus in the left anterior inferior parietal cortex were exclusively activated in innate right-handers. In contrast, distinct foci in the right anterior parietal lobule and the right parietal operculum, covering the secondary somatosensory cortex, were selectively active during right-hand writing in converted left-handers. In addition, innate left-handers showed only a right-sided activation of the parietal cortex during left-hand writing.

Because visual feedback was denied in our study, participants had to rely on previous knowledge, internal feedback from the motor outflow ("efferent copy"), and kinesthetic feedback to estimate their writing movements. The lateralized activation pattern in anterior parietal areas may therefore reflect a kinesthetic representation of writing movements in the parietal cortex contralaterally to the innately preferred hand. Indeed, lesion and functional imaging studies in humans suggest that anterior modules of the human parietal cortex, especially the superior parietal lobule, are related to elaboration of somatosensory input (Roland, 1987; Pause et al., 1989; Binkowski et al., 1999). These somatosensory functions of the parietal cortex include a critical role in generating and maintaining a kinesthetic model of ongoing movements (Sirigu et al., 1996, 1999) and spatiotemporal organization of complex movements (Weiss et al., 2001). Our findings suggest that this also applies to handwriting, regardless of the direction of handedness or conversion at a young age.

The right anterior supramarginal gyrus showed a graded increase in functional activation with the degree of left-handedness. This observation may be explained by motor preparation before actual handwriting. Our participants needed $\sim 2 \mathrm{sec}$ to write the target word. Because the writing task was paced every $6 \mathrm{sec}$, participants had several seconds left for motor preparation until the next "go" signal. Functional imaging studies on innate righthanders suggested a dominant role in movement preparation and selection for the left inferior parietal lobule (Deiber et al., 1996; Krams et al., 1998; Schluter et al., 2001). Accordingly, lesions of the left supramarginal gyrus impair normal covert motor preparation (Rushworth et al., 1997). Therefore, the positive relationship between functional activity in the right supramarginal gyrus and the degree of left-handedness might indicate a greater effort related to movement preparation in left-handers, who, as mentioned above, may have had more difficulty with task initiation.

\section{Temporal cortex}

Although auditory input was matched between the writing and baseline conditions, the behavioral relevance of listening to the tone differed between conditions, because the tone served as the go signal in the handwriting condition only. Converted lefthanders showed a relatively stronger writing-related activation of the posteromedial part of the right superior temporal gyrus, which forms part of the auditory association cortex (Zatorre and Belin, 2001). This differential activation pattern suggests a functional asymmetry of auditory processing related to the direction of handedness. This concept corroborates morphometric MRI studies that demonstrated a weaker leftward asymmetry of the planum temporale in left-handers as opposed to right-handers (Steinmetz, 1996). Alternatively, the activation pattern in the superior temporal gyrus may be related to the language aspect of writing and thus indicate a less pronounced left-hemispheric dominance for language in converted left-handers compared with right-handers (Knecht et al., 2000).

\section{SM1}

The hand area of the SM1 unexpectedly demonstrated no interhemispheric differences in writing-related activation between right-handers and converted left-handers. At first glance, this finding is in contrast to studies that reported structural and functional differences in SM1 $1_{\text {HAND }}$ depending on the direction or degree of handedness (Yoshii et al., 1989; Kim et al., 1993; 
Triggs et al., 1994, 1997; Amunts et al., 1996; Dassonville et al., 1997; Volkmann et al., 1998). However, these studies did not control for proficiency in handwriting skills. This is particularly relevant when investigating task-related changes in neural activity, because the SM1 is subject to profound long-term reorganization as a result of motor practice and learning (Jenkins et al., 1990; Sanes et al., 1992; Pascual-Leone et al., 1994; Karni et al., 1995; Xerri et al., 1999). Therefore, long-term differences in motor practice could have caused functional and structural differences between the dominant and nondominant SM1 in previous studies. Furthermore, previously reported ipsilateral activations of SM1 during movements of the nondominant hand were perhaps caused by a lower automaticity of movement performance (Mattay et al., 1998; Schluter et al., 2001). These two mechanisms (use-dependent cortical plasticity and reduced automaticity) played a much smaller role in our study. The absent relationship between neural activity in the SM1 and handedness in the present study suggests that asymmetries in the SM1 primarily reflect a long-term consequence of handedness, rather than its primary driving source.

\section{Conclusion}

Adult converted left-handers show persistent features of lefthandedness during right-hand writing. Extending previous studies, which emphasized functional asymmetries at the executive level of the motor system (e.g., the SM1), our results provide evidence for a neural substrate of human handedness in premotor and parietal motor association areas.

\section{REFERENCES}

Amunts K, Schlaug G, Schleicher A, Steinmetz H, Dabringhaus A, Roland PE, Zilles K (1996) Asymmetry in the human motor cortex and handedness. NeuroImage 4:216-222.

Amunts K, Jancke L, Mohlberg H, Steinmetz H, Zilles K (2000) Interhemispheric asymmetry of the human motor cortex related to handedness and gender. Neuropsychologia 38:304-312.

Binkowski F, Buccino G, Posse S, Seitz RJ, Rizzolatti G, Freund H (1999) A fronto-parietal circuit for object manipulation in man: evidence from an fMRI study. Eur J Neurosci 11:3276-3286.

Boecker H, Dagher A, Ceballos-Baumann AO, Passingham RE, Samuel M, Friston KJ, Poline J, Dettmers C, Conrad B, Brooks DJ (1998) Role of the human rostral supplementary motor area and the basal ganglia in motor sequence control: investigations with $\mathrm{H}_{2}{ }^{15} \mathrm{O} \mathrm{PET}$. J Neurophysiol 79:1070-1080.

Dassonville P, Zhu XH, Ugurbil K, Kim SG, Ashe J (1997) Functional activation in motor cortex reflects the direction and the degree of handedness. Proc Natl Acad Sci USA 94:14015-14018.

Deiber MP, Passingham RE, Colebatch JG, Friston KJ, Nixon PD, Frackowiak RS (1991) Cortical areas and the selection of movement: a study with positron emission tomography. Exp Brain Res 84:393-402.

Deiber MB, Ibanez V, Sadato N, Hallett M (1996) Cerebral structures participating in motor preparation in humans: a positron emission tomography study. J Neurophysiol 75:233-247.

Deiber MB, Honda M, Ibanez V, Sadato N, Hallett M (1999) Mesial motor areas in self-initiated versus externally triggered movements examined with fMRI: effect of movement type and rate. J Neurophysiol 81:3065-3077.

Eichhorn TE, Gasser T, Mai N, Marquardt C, Arnold G, Schwarz J, Oertel WH (1996) Computational analysis of open loop handwriting movements in Parkinson's disease: a rapid method to detect dopamimetic effects. Mov Disord 11:289-297.

Fox PT, Mintun MA (1989) Noninvasive functional brain mapping by change-distribution analysis of averaged PET images of $\mathrm{H}_{2}{ }^{15} \mathrm{O}$ tissue activity. J Nucl Med 30:141-149.

Friston KJ, Frith CD, Liddle PF, Dolan RJ, Lammertsma AA, Frackowiak RSJ (1990) The relationship between global and local changes in PET scans. J Cereb Blood Flow Metab 10:458-466.

Friston KJ, Frith CD, Liddle PF, Frackowiak RSJ (1991) Comparing functional (PET) images: the assessment of significant change. J Cereb Blood Flow Metab 11:690-699.

Friston KJ, Ashburger J, Poline JB, Frith CD, Heather JD, Frackowiak RSJ (1995a) Spatial registration and normalization of images. Hum Brain Mapp 2:1-25.

Friston KJ, Holmes A, Worsley KJ, Poline JB, Frith CD, Frackowiak RSJ (1995b) Statistical parametric maps in functional imaging: general linear approach. Hum Brain Mapp 2:189-210.

Gilbert AN, Wysocki CJ (1992) Hand preference and age in the United States. Neuropsychologia 30:601-608.

Haaland KY, Harrington DL (1996) Hemispheric asymmetry of movement. Curr Opin Neurobiol 6:796-800.

Hikosaka O, Sakai K, Miyauchi S, Takino R, Sasaki Y, Pütz B (1996) Activation of the human presupplementary motor area in learning of sequential procedures: a functional MRI study. J Neurophysiol 76:617-621.

Humberstone M, Sawle GV, Clare S, Hykin J, Coxon R, Bowtell R, Macdonald IA, Morris PG (1997) Functional magnetic resonance imaging of single motor events reveals human presupplementary motor area. Ann Neurol 42:632-637.

Hollerbach JM (1981) An oscillation theory of handwriting. Biol Cybern 39:139-156

Jenkins IH, Brooks DJ, Nixon PD, Frackowiak RS, Passingham RE (1994) Motor sequence learning: a study with positron emission tomography. J Neurosci 14:3775-3790.

Jenkins WM, Merzenich MM, Ochs MT, Allard T, Guic-Robles E (1990) Functional reorganization of primary somatosensory cortex in adult owl monkeys after behaviorally controlled tactile stimulation. J Neurophysiol 63:82-104.

Jueptner M, Stephan KM, Frith CD, Brooks DJ, Frackowiak RS, Passingham RE (1997) Anatomy of motor learning. I. Frontal cortex and attention to action. J Neurophysiol 77:1313-1324.

Karni A, Meyer G, Jezzard P, Adams MM, Turner R, Ungerleider LG (1995) Functional MRI evidence for adult motor cortex plasticity during motor skill learning. Nature 377:155-158.

Kawashima R, Inoue K, Sato K, Fukuda H (1997) Functional asymmetry of cortical motor control in left-handed subjects. NeuroReport 8:1729-1732.

Kim SG, Ashe J, Hendrich K, Ellermann JM, Merkle H, Ugurbil K, Georgopoulos AP (1993) Functional magnetic resonance imaging of motor cortex: hemispheric asymmetry and handedness. Science 261:615-617.

Knecht S, Drager B, Deppe M, Bobe L, Lohmann H, Floel A, Ringelstein EB, Henningsen H (2000) Handedness and hemispheric language dominance in healthy humans. Brain 123:2512-2518.

Krams M, Rushworth MF, Deiber MP, Frackowiak RS, Passingham RE (1998) The preparation, execution, and suppression of copied movements in the human brain. Exp Brain Res 120:386-398.

Marquardt C, Mai N (1994) Computational procedures for movement analysis in handwriting. J Neurosci Methods 52:39-45.

Marquardt C, Gentz W, Mai N (1999) Visual control of automated handwriting movements. Exp Brain Res 128:224-228.

Mattay VS, Callicott JH, Bertolino A, Santha AK, Van Horn JD, Tallent KA, Frank JA, Weinberger DR (1998) Hemispheric control of motor function: a whole brain echo planar fMRI study. Psychiatry Res 83:7-22.

Morasso P, Mussa Ivaldi FA (1982) Trajectory formation and handwriting. Biol Cybern 45:131-142.

Nagahama Y, Okada T, Katsumi Y, Hayashi T, Yamauchi H, Sawamoto N, Toma K, Nakamura K, Hanakawa T, Konishi J, Fukuyama H, Shibasaki H (1999) Transient neural activity in the medial superior frontal gyrus and precuneus time locked with attention shift between object features. NeuroImage 10:193-199.

Oldfield RC (1971) The assessment and analysis of handedness: the Edinburgh inventory. Neuropsychologia 9:97-113.

Pascual-Leone A, Grafman J, Hallett M (1994) Modulation of cortical motor output maps during development of implicit and explicit knowledge. Science 263:1287-1289.

Pause M, Kunesch E, Binkofski F, Freund HJ (1989) Sensorimotor disturbances in patients with lesions of the parietal cortex. Brain 112:1599-1625.

Peters M (1991) Laterality and motor control. Ciba Found Symp 162:300-308.

Plamondon R (1995) A kinematic theory of rapid human movements. I. Movement representation and generation. Biol Cybern 72:295-307.

Porac C, Buller T (1990) Overt attempts to change hand preference: a study of group and individual characteristics. Can J Psychol 44:512-521.

Porac C, Friesen IC (2000) Hand preference side and its relation to hand preference switch history among old and oldest-old adults. Dev Neuropsychol 17:225-239.

Rintjes M, Dettmers C, Büchel C, Kiebel S, Frackowiak RSJ, Weiller CA (1999) Blueprint for movement: functional and anatomical representations in the human motor system. J Neurosci 15:8043-8048.

Roland PE (1987) Somatosensory detection of microgeometry, macrogeometry, and kinaesthesia after localized lesions of the cerebral hemispheres in man. Brain Res 434:43-94.

Rushworth MF, Nixon PD, Renowden S, Wade DT, Passingham RE (1997) The left parietal cortex and motor attention. Neuropsychologia 35:1261-1273.

Sakai K, Hikosaka O, Miyauchi S, Sasaki Y, Fujimaki N, Putz B (1999) 
Presupplementary motor area activation during sequence learning reflects visuo-motor association. J Neurosci 19:RC1:1-6.

Sakai K, Hikosaka O, Takino R, Miyauchi S, Nielsen M, Tamada T (2000) What and when: parallel and convergent processing in motor control. J Neurosci 20:2691-2700.

Sanes JN, Wang J, Donoghue JP (1992) Immediate and delayed changes of rat motor cortical output representation with new forelimb configurations. Cereb Cortex 2:141-152.

Schluter ND, Rushworth MF, Passingham RE, Mills KR (1998) Temporary interference in human lateral premotor cortex suggests dominance for the selection of movements: a study using transcranial magnetic stimulation. Brain 121:785-799.

Schluter ND, Krams M, Rushworth MF, Passingham RE (2001) Cerebral dominance for action in the human brain: the selection of actions. Neuropsychologia 39:105-113.

Siebner HR, Tormos JM, Ceballos-Baumann AO, Auer C, Catala MD, Conrad B, Pascual-Leone A (1999) Low-frequency repetitive transcranial magnetic stimulation of the motor cortex in writer's cramp. Neurology 52:529-537.

Sirigu A, Duhamel JR, Cohen L, Pillon B, Dubois B, Agid Y (1996) The mental representation of hand movements after parietal cortex damage. Science 273:1564-1568.

Sirigu A, Daprati E, Pradat-Diehl P, Franck N, Jeannerod M (1999) Perception of self-generated movement following left parietal lesion. Brain 122:1867-1874.

Steinmetz H (1996) Structure, function, and cerebral asymmetry: in vivo morphometry of the planum temporale. Neurosci Biobehav Rev 20:587-591.

Talairach J, Tournoux P (1988) Co-planar stereotaxic atlas of the human brain. New York: Thieme.

Tanji J (1996) New concepts of the supplementary motor area. Curr Opin Neurobiol 6:782-787.

Teasdale TW, Owen DR (2001) Cognitive abilities in left-handers: writing posture revisited. Neuropsychologia 39:881-884.
Toni I, Krams M, Turner R, Passingham RE (1998) The time course of changes during motor sequence learning: a whole-brain fMRI study. NeuroImage 8:50-61.

Triggs WJ, Calvanio R, Macdonell RAL, Cros D, Chiappa KH (1994) Physiological motor asymmetry in human handedness: evidence from transcranial magnetic stimulation. Brain Res 636:270-276.

Triggs WJ, Calvanio R, Levine M (1997) Transcranial magnetic stimulation reveals a hemispheric asymmetry correlate of intermanual differences in motor performance. Neuropsychologia 35:1355-1363.

Vivani P, Perani D, Grassi F, Bettinardi V, Fazio F (1998) Hemispheric asymmetries and bimanual asynchrony in left- and right-handers. Exp Brain Res 120:531-536.

Volkmann J, Schnitzler A, Witte OW, Freund HJ (1998) Handedness and asymmetry of hand representation in human motor cortex. J Neurophysiol 79:2149-2154.

Waldvogel D, van Gelderen P, Muellbacher W, Ziemann U, Immisch I, Hallett M (2000) The relative metabolic demand of inhibition and excitation. Nature 406:995-998.

Weiss PH, Dohle C, Binkowski F, Schnitzler A, Freund HJ, Hefter H (2001) Motor impairment in patients with parietal lesions: disturbances of meaningless arm movement sequences. Neuropsychologia 39:397-405.

Worsley KL, Evans AC, Marrett S, Neelin P (1992) A three-dimensional statistical analysis for CBF activation studies in human brain. J Cereb Blood Flow Metab 12:900-918.

Xerri C, Merzenich MM, Jenkins W, Santucci S (1999) Representational plasticity in cortical area $3 \mathrm{~b}$ paralleling tactual-motor skill acquisition in adult monkeys. Cereb Cortex 9:264-276.

Yoshii F, Ginsberg MD, Kelley RE, Chang JY, Barker WW, Ingenito G, Apicella AM, Globus MYT, Duara R, Boothe TE (1989) Asymmetric somatosensory activation with right- vs left-hand stimulation: a positron emission tomographic study. Brain Res 483:355-360.

Zatorre RJ, Belin P (2001) Spectral and temporal processing in human auditory cortex. Cereb Cortex 11:946-953. 